\title{
EL POBLAMIENTO Y EL PROCESO DE LA SECUENCIA CULTURAL PRE- HISTÓRICA DE LA CUENCA DEL PLATA
}

\author{
Jorge Amilcar Rodríguez
}

\section{1.-Introducción}

En este trabajo se analizarán estos aspectos arqueológicos en el área oriental de la Cuenca del Plata: el este del Paraguay, el sudeste de Brasil, la Mesopotamia Argentina y el Uruguay. Esta área no muestra uniformidad ambiental, sino alta diversidad de ambientes (biomas) que se intercalan a lo largo y a lo ancho de la misma, presentando notorias diferencias topográficas, climáticas, florísticas, faunísticas, geológicas y edáficas.

Varias regiones de la cuenca del Plata tienen alguna similitud cultural, ya que varias de las tradiciones (Ej.: Paleoindígena, Humaita, Ivaí, Umbú, Tupiguaraní, Planáltica) que la ocuparon se dispersaron o migraron a diversas regiones de la cuenca, gestándose por eso diversos tipos culturales de la misma tradición. Por esto algunas regiones (zonas) de la Mesopotamia tuvieron algún vínculo cultural con otras regiones de la cuenca. Se han podido develar algunas evidencias acerca de cómo y porqué se produjeron las dispersiones, expansiones y migraciones.

El principal objetivo de plantear cómo fue el poblamiento y el desarrollo prehistórico de la cuenca del Plata, básicamente de la Mesopotamia, es para aportar información que permita comparar y poder establecer si existieron algunas similitudes y/o altas diferencias entre las entidades culturales que poblaron esta área y el gran Chaco meridional.

Por las evidencias que se han descubierto hasta ahora en el poblamiento prehistórico de la cuenca del Plata y del Chaco hubo una marcada diferencia. Como son dos territorios (ambientes) con significativas diferencias probablemente motivaron distintas adaptaciones culturales. Quizás este fue uno de los motivos que gestó desigualdad cultural entre ambas áreas. Es factible que incluso algunas entidades que poblaron el Chaco y otras que poblaron la otra área hayan tenido los mismos ancestros, tradición (Ej. Tupiguaraní, Pantanal), pero se diversificaron por esa diferencia ambiental. La zona del Chaco adyacente al Paraná y la oriental de Corrientes también adyacente al Paraná que tienen algunas similitudes ambientales muestran entidades con cierta semejanza cultural (Ej. tradición Ribereña Paranaense).

Estoy en conocimiento de diversos aspectos del poblamiento prehistórico de la cuenca del Plata y de algunos rasgos culturales de las entidades que la poblaron porque desde el inicio de mis investigaciones arqueológicas en Corrientes y Entre Ríos verifiqué que, para poder interpretar mejor las evidencias que uno detecta, no es apropiado reducirse a un sitio o a unos pocos sitios de una localidad (de una limitada zona geográfica), ni tampoco limitarse a una región, sino que es necesario tener un profundo conocimiento de regiones vecinas (adyacentes) y poder cotejar, comparar, lo detectado en esas diversas áreas. Esto 
aporta a poder interpretar mejor cómo se gestaron las distintas entidades y cómo se produjo la secuencia y el desarrollo cultural.

Las unidades o categorías sistemáticas que aplicaremos en este trabajo son: Tradición, Tipo Cultural, Complejo Cultural. En la sistemática adoptada para esta cuenca ha predominado Tradición como unidad de integración, estoy conciente de las limitaciones y problemas que la afectan a su concepción (histórico-cultural) y aplicación tradicional; pero la continúo aplicando porque la mayoría de las entidades definidas en esta cuenca están denominadas con ese término, por eso la aplico con una concepción diferente, relacionada a otro marco teórico-metodológico y a otro tipo de esquema sistemático (Rodríguez 1986). Tradición: es una unidad integrativa temporo-cultural. Un conjunto de manifestaciones culturales genéticamente relacionadas, por lo que comparten ciertas propiedades o rasgos básicos en distintos componentes de su cultura material. En consecuencia el conjunto muestra afinidades que la identifican y la distinguen de otras. En una misma tradición se produjeron diversificaciones diacrónicas y espaciales sincrónicas. Por eso no es equivalente a un conjunto o sistema cultural totalmente homogéneo y uniforme (Ej. una Cultura), ni tampoco a una unidad racial, lingüística o étnica.

Tipo Cultural: una manifestación o conjunto de manifestaciones culturales que comparten la mayoría de los rasgos culturales. Pueden ser diversificaciones adaptativas o sociales en una misma tradición, sincrónicas -en distintos ambientes- o diacrónicas. Esta unidad sí equivale a una Cultura. Complejo Cultural lo aplicó a una manifestación específica de una tradición, que no se ha podido definir todavía como Tipo Cultural.

Aunque ya son numerosas y diversas las entidades detectadas y definidas en las distintas regiones y periodos cronológicos para esta cuenca, producto de numerosas e intensas investigaciones no se puede presentar esto como algo definitivo, queda la posibilidad que la profundización y extensión de la investigación posibilite descubrir otras nuevas evidencias y también que se modifique o complemente lo que aquí se presenta.

Como en esta cuenca predominó en la mayor parte de la prehistoria el poblamiento de amerindios cazadores-recolectores esto es otro de los motivos que complica el develamiento y la interpretación de cómo fue la cultura y otros aspectos de estos pueblos. Porque los rastros, el registro arqueológico que nos han dejado en los asentamientos es restringido, insuficiente y por lo general no muy significativos. También porque por las características que tiene ese registro y los lugares donde se asentaron genera una mayor posibilidad de que sean afectados o deteriorados por diversos agentes naturales. Por eso y otras razones epistemológicas lo que expongo aquí considero que es una interpretación preliminar, hipótesis a confirmar.

\section{2.-El medio ambiente actual}

La cuenca del Plata por su extendido territorio, por la diversidad de humedales y por las características de sus tres destacados ríos (el Paraná, Uruguay y Paraguay) se encuentra en la actualidad entre las más relevantes del planeta. El Paraná por la extensión de su curso, 
la cantidad y relevancia de sus afluentes, el territorio que abarca su cuenca, el caudal que transporta y que descarga, queda calificado como el más destacado de este sistema. Las características de su llanura aluvial, su cauce central, su caudal, los márgenes de su valle aluvial, muestran diferencias en sus distintos tramos. Cuando se considera toda la extensión de su curso sus tramos son: como Alto desde su nacimiento hasta Posadas, Medio desde aquí hasta la desembocadura del Paraguay y como Bajo desde aquí hasta su Delta.

El Paraguay también tiene una cuenca extensa y diversificada y aunque no tiene un elevado caudal es el que drena el Pantanal que es el estero más extenso de Sudamérica. El tramo bajo (argentino-paraguayo) tiene una llanura aluvial de 5 a $15 \mathrm{Km}$. de ancho, caracterizada por un gran número de bañados y pantanos y también por meandros actuales y antiguos (Iriondo 1991).

El río Uruguay presenta algunas características que lo distinguen del Paraguay y el Paraná, particularmente lo diferencian notoriamente del Paraná medio y bajo. Su llanura aluvial es reducida y se limita generalmente a su cauce principal. En sus tramos alto y medio experimenta una marcada transición, su nivel de base experimenta una gradual declinación, además presenta afloramientos rocosos (de basalto) en el cauce, que originan rápidos, saltos y correderas; la llanura aluvial es relativamente estrecha y su cauce está bordeado por márgenes con una topografía generalmente alta, relativamente plana con terrazas y albardones y en algunos tramos con lomadas. En su tramo bajo su cauce se extiende y hay mayor cantidad de islas y sus márgenes van bajando. En tal sentido a este río es posible considerarlo como un ámbito ecológico con características distintivas.

Los sectores septentrional y meridional de la cuenca del Plata muestran características ambientales (Ej. topográficas, hidrológicas, vegetativas y geomorfológicas) con marcadas diferencias. El sector norte y central es parte del Planalto, que exhibe sus mayores alturas en las sierras próximas a la costa atlántica, descendiendo gradualmente desde allí hacia el oeste y el sur; la vegetación predominante son diferentes tipos de selvas y sabanas -Ej. Cerrados-. En el sector meridional predominan las llanuras, aunque en su parte norte y oriental también hay zonas elevadas y onduladas, en cambio hacia el oeste y el sur es deprimida la superficie; la vegetación dominante es la pradera, con presencia de bosques xerofíticos, sabanas y selva en galería. (Clapperton 1993; Morrone 2001).

Los climas que predominan en esta cuenca son tropical, subtropical y templado. Los tres exhiben variaciones estacionales de acuerdo a la zona en que están, en lo que respecta a la temperatura, precipitaciones, humedad, evapotranspiración, presión y dinámica atmosférica. Si bien a nivel general se percibe un crecimiento gradual de la temperatura $\mathrm{y}$ de las precipitaciones medias de sur a norte, esto no es un patrón que se mantenga de manera continua y uniforme, se ve alterado en algunas zonas por la topografía y/o algún otro factor local. Por ejemplo en las altas cuencas de los ríos Uruguay e Iguazú, está la zona con mayores precipitaciones -que sobrepasan los $3.000 \mathrm{~mm}$ en algunos años-, mientras que en algunas zonas más al norte no sobrepasan los $2.000 \mathrm{~mm}$. (Morrone 2001). En el norte de la Mesopotamia -norte de Corrientes y Misiones- según la zona, el clima varía. A la 
misma latitud, en zonas elevadas de la parte meridional del Planalto, en invierno y otoño el frío llega a ser intenso.

En esta cuenca las formaciones vegetales presentes son: Selva Tropical (en su sector septentrional), Selva Subtropical (en el este y sur del Planalto), Selva con Araucaria (en algunos sectores del Planalto), Selva Pluvial Atlántica (en la sierra del litoral atlántico), Selva en Galería (al margen de los ríos), Cerrado (sectores del norte del área), Bosque Xerófilo (en el centro de la Mesopotamia), Sabana, Praderas y Pastizales (en el sector meridional y algunos parches del Planalto). (Ledru et. al., 1998; Behling et. al., 2001).

Lo mencionado son algunos de los factores que generan la diversidad ambiental, que ha tenido implicancias en el poblamiento y el desarrollo cultural prehistórico. Algunos de los ambientes más típicos son: llanura aluvial Paraná medio y bajo, Estero del Iberá, Alta Cuenca del Paraná, humedales del Planalto, alta cuenca del Uruguay, Uruguay medio, zona Deltaíca, Pantanal, río Paraguay, etc.

\section{3.-Paleoambientes del Pleistoceno Final y el Holoceno}

Entre los investigadores de paleoecología que han detectado evidencias y han aportado interpretaciones sobre las oscilaciones climáticas en el área, podemos mencionar: para el Nordeste argentino y planicies de Sudamérica Iriondo (1991, 1999), Iriondo y García (1993), para el sector meridional del Planalto Behling (1998), Salgado-Labouriau et. al. (1998), Turcq et. al. (1997) para la parte norte del área en estudio Stevaux (2000), Servant et. al. (1989). En la última década se han realizado varios estudios palinológicos en esta área (Behling 1998), (Ledru et. al., 1998). Los diagramas polínicos muestran que se han producido fluctuaciones en la composición de la vegetación durante el Holoceno debido a cambios climáticos de importancia. Otro proveniente de un depósito de turba de Río Grande do Sul indica que alrededor de 11,000 A.P. ya hubo un evento cálido y con intensas precipitaciones (Roth y Lorscheitter 1989).

Interrelacionando las evidencias aportadas por los autores mencionados y desde distintas disciplinas -Geología, Palinología, Paleoecología, Biogeografía, climatología, Arqueología- y de distintas regiones del área se puede esbozar, como una síntesis, un esquema general de los climas y ambientes de los últimos 15.000 años, con una secuencia detallada de los eventos más destacados que se sucedieron:

En el Pleistoceno final, por lo menos hasta el 13.000 A.P. prevaleció el clima frío y seco (árido) y la vegetación cerrada -selva- mantuvo una pronunciada retracción a favor de las formaciones abiertas -estepa, sabana y xerofíticas (monte espinoso). Entre el 13.000 y el 10.000 se da ya un progresivo cambio del clima, el frío y la aridez continúan pero atemperados y con alternancia de eventos templados y con intensas precipitaciones; es decir, aunque hay cambios se dan reiteradas reversiones al clima previo. A partir del 10.000 A.P. se inicia el afianzamiento de un clima cálido y húmedo de manera gradual y también todavía con interrupciones o reversiones. Entre el 9.000 y 8.000 A.P. hay evidencias que sugieren que se mantuvo la alta temperatura pero vino de nuevo la aridez. Después de este evento 
continuó el aumento de la temperatura y las precipitaciones, que alcanzaron sus máximas con el Optimun Climaticum entre el 6.500 y 5.500 A.P. El nivel del mar estaba 3-5 m más alto que el actual. Hay que señalar la ingresión que afectó la zona deltaica alrededor del 5.000 A.P.

Aunque la vegetación del área fue un mosaico de distintas formaciones que alternaron su dominancia y el espacio ocupado, las formaciones vegetales cerradas se extendieron y dispersaron y las abiertas se hicieron más verdes. Esto afectó también a parte de la fauna, que también se dispersó ocupando nuevas áreas.

Es preciso señalar que estas condiciones climáticas cálidas, de altas temperaturas, humedad e intensas precipitaciones; climas tropicales y subtropicales que tuvieron algunas variantes según cada región, que prevalecieron sobre todo durante el Holoceno Inferior y Medio (10.000 -3.500 AP) fueron interrumpidos por eventos áridos y descenso de temperatura, algunos de carácter global y otros regional: -al menos hubo variantes regionales en cuanto a su intensidad y su extensión temporal- que se dieron en los siguientes momentos: 7.000 - 6.500; 5.000 - 4.000; 3.500 - 2.000 A.P., otros más cortos y de menor alcance se dieron alrededor del 1.700, 700 y 300 AP.,(Stevaux 2000; Iriondo 1999).

Luego emergió un nuevo evento cálido-húmedo: la edad Cálida Medieval, que tuvo lugar entre el 700 y 1.200 DC. Se intensificó el impacto del anticiclón subatlántico. Alguna evidencia indica que hubo una extensión hacia el sur de condiciones tropicales hoy imperantes en Misiones; tal como lo sugiere la presencia en Salto Grande de moluscos Felipponea Iheringi, en la actualidad retirados de nuevo más al norte (Rodríguez y Rodríguez 1985).

La Pequeña Edad del Hielo entre 1400 y 1850 D.C. recreó las condiciones mencionadas para el Pleistoceno aunque en una escala de intensidad menor. Aunque sus efectos parecen no haber llegado al norte del nordeste, al menos de la misma forma que se presentó más al sur.

En Corrientes hay evidencias de formación de nuevos cursos y/o ampliación de los ya existentes durante el Holoceno medio. En la actualidad se observan como paleocauces o como cursos reducidos o restringidos. Este territorio en sus zonas bajas -que abarca una amplia extensión- debe haber estado inundado casi de continuo en ese tiempo, por eso las ocupaciones humanas se dieron en las zonas altas -Nordeste de la provincia, YacyretáApipé, Cuenca del Uruguay y el Sudeste (Paiubre). Debe haber habido también una amplia e intensa dispersión de formaciones selváticas en el nordeste y norte de Corrientes, por eso quedaron los relictos -Mogotes- que hoy se observan.

Es muy probable que la llanura aluvial del bajo Paraná y el estero Iberá durante el Holoceno Medio hayan estado también inundados casi de continuo debido a la gran intensidad de las precipitaciones, así como por las transgresiones que experimentó su delta -por el aumento del nivel del mar alrededor de 5.700 y 4.000 A.P.-. Este podría ser el motivo por el cual estas regiones no fueron pobladas durante este período, no se han detectado sitios preceramicos, según las evidencias que se dispone se ocuparon en el Holoceno Superior. 


\section{4.-Entidades culturales prehistóricas de la Cuenca del Plata}

\section{1-Entidades Precerámicas (Cazadores-Recolectores)}

4.1.1-Tradición Paleoindígena (Tipos culturales: Uruguay, Uruguay I, Planalto I): Por lo detectado hasta ahora pobló inicialmente el río Uruguay medio 12.000 A.P. y luego algunos de su afluentes y el planalto meridional. Los sitios se localizan en lugares elevados del margen del río y próximos a las confluencias de pequeños cauces o paleocauces.

Los artefactos más representativos son las puntas de Proyectil pedunculadas con morfología del limbo triangular y algunas cola de pescado y otros instrumentos bifaciales manufacturados por percusión y presión bifacial. Además incluye otros artefactos manufacturados por percusión directa unifacial (Ej. Choppers, Raspadores, Perforadores, nucleiformes y lascas con rastros).

4.1.2-Tradición Humaitá: En la Mesopotamia le he podido definir como tipos Culturales: Yacyreta II, 3 de Mayo, Altoparanaense, Cuareimense. Pobló básicamente sectores del Planalto meridional: tramos del Paraná alto y medio y algunos de sus afluentes, tramos del Uruguay alto y medio y su afluentes y el Jacuí. Ya se suman unos 250 sitios, generalmente se localizan en lugares elevados de los márgenes de los cursos acuáticos y el ambiente más típico es el Planalto o mesetas vinculadas a este cubiertos por selva subtropical con araucaria.

Los artefactos tienen como características significativas que tienen buen y extendido tallado, definida y típica morfología y un tamaño grande (Ej. Clavas, Hachas de mano, Picos, Raspadores, Perforadores, Muescas). Se supone que tuvieron como funcionalidad prioritaria la recolección y el procesamiento de diversos recursos vegetales (Ej. ramas, troncos, raíces, etc.). Su cronología se extiende desde 8.000 al 1.000 A.P..

4.1.3.-La Tradición Umbú: Ya se han descubierto unos 500 sitios. En la Mesopotamia ya le identifiqué tres tipos culturales: Uruguay II, Uruguay III, Gualeguay. Es una de las entidades precerámicas que tuvo una mayor dispersión en la cuenca del Plata y que tuvo gran persistencia temporal, entre 8.500 y 600 A.P. Pobló la zona central y meridional de la cuenca y con más intensidad sus sectores orientales: sectores del planalto, cuenca del río Uruguay, sector meridional del alto Paraná y algunos de sus afluentes. La mayor concentración, densidad de sitios, parece ocurrir en el borde meridional del Planalto (Ej. ríos Jacuí, Caí, Dos Sinos). Tiene algunas diferencias pero también similitudes con Paleoindígena, esto y la región donde se originó Umbú, la última antes mencionada, sugiere que se pudo haber gestado, derivado, de Paleoindígena, que fue su ancestro. Ocupo básicamente los ambientes bajos y llanos y con las formaciones vegetales: sabanas, praderas, selva marginal y selva de araucaria. Los sitios están generalmente al margen o próximos a los humedales (ríos, arroyos, lagunas o bañados), en algunos sectores del planalto algo mas alejados de estos. Son sitios abiertos, pero también unos pocos están en cuevas. En estos últimos son casi los únicos donde se pudo encontrar restos orgánicos (restos faunísticos de subsistencia y esqueletarios humanos).

Tiene como más característicos los mismos artefactos de Paleoindígena, manufacturados por la misma tecnología; la diferencia es básicamente en el estilo, la morfología y el tamaño de las puntas de Proyectil y en los tipos de los otros artefactos 
unifaciales (Ej.: raspadores, perforadores, muescas, choppers, lascas con rastros). Contaban también con artefactos pulidos (Ej: Boleadoras).

4.1.4.-La tradición Ivaí: En la Mesopotamia ya tiene definidos como tipos culturales Yacyreta I, Los Mogotes, La Paloma, El Paiubre. Pobló reducidos sectores de la cuenca del alto Paraná (Matto Grosso do Sul, Paraná, Misiones y Corrientes) y el río Uruguay medio. Tuvo su persistencia temporal entre 7.000 y 2.000 A.P. En el ambiente que ocupó predomino el clima calido y la vegetación: la selva subtropical y la selva en galería. Los sitios se emplazan básicamente en la margen de ríos relevantes y coincide en varios casos con la presencia de saltos, correderas (rápidos), afloramientos rocosos e islas en el curso del río.

La tecnología lítica de esta entidad se caracteriza por ser percusión directa unifacial con cierta rusticidad y restringida. Los artefactos más típicos son diversos tipos de Raspadores y Raederas, Muescas, Perforadores, Buriles. También varios artefactos pulidos.

En la llanura aluvial del Bajo Paraná (desde la confluencia del paraguay hasta el delta), las zonas vecinas (adyacentes) de Corrientes, Chaco, Entre Ríos y Santa Fe y en el estero del Iberá, no se han detectado sitios precerámicos. Por las evidencias disponibles parecen no haber sido poblados en el Holoceno inferior y medio, recién a partir del 2.500 A.P.. Uno de los motivos puede ser que estos humedales en el Holoceno medio estuvieron habitualmente inundados por las altas precipitaciones que hubo y también por el alto nivel del mar que afectó la desembocadura y el delta del Paraná. Otro motivo puede ser que esa región no disponía de materias primas líticas y como ya se comentó las entidades que poblaron las otras regiones de la cuenca se asentaban donde disponían de diversas materias primas para manufacturar líticos.

\section{2.-Entidades Ceramolíticas (cazadores-recolectores)}

4.2.1.-Tradición Sabanas Bajas (Tipo cultural: Yacyretá III, Salto Grande, Cerro Chico, Guavirabi): Los sitios detectados se distribuyen en la cuenca del río Uruguay medio y un tramo del Paraná medio, cursos del interior de Entre Ríos y lugares escasos del bajo Paraná. Los sitios están emplazados en el margen de los grandes ríos y algunos de sus afluentes.

La cerámica en su manufactura, su cocción, el tratamiento de la superficie y la decoración son rudimentarias. El color mas frecuente es sepia. Las formas de las vasijas son de contorno simple, reducido tamaño y sin asa ni apéndices. La decoración plástica es siempre motivos geométricos y sencillos (Ej.: Inciso, Punteado, Modelado). Otros materiales detectados fueron artefactos líticos, instrumentos de hueso y restos faunísticos. Los asentamientos son reducidos en su extensión superficial. La cronología por las dataciones obtenidas se extiende entre 2.500 al 700 A.P.

4.2.2.-Tradición Platense (complejo Ibicueña): Se distribuye en la zona más meridional de la cuenca: la cuenca del bajo Uruguay, algunos sectores del delta y ambas márgenes del río de La Plata. Están localizados en los márgenes o próximos a estos y emplazados en albardones u otras elevaciones naturales de esa zona (Ej. montículos). 
La cerámica tiene características mejores que la entidad antes mencionada; el color habitual es sepia y naranja, la decoración plástica tiene cierta complejidad (Ej.: Inciso, Punteado impreso). Las formas de las vasijas son semejantes a la antes descripta. Además de cerámica se detectaron artefactos líticos tallados y pulidos, puntas de Proyectil y diversos artefactos de hueso bien elaborados.

No se dispone dataciones para establecer su cronología, pero deber ser posterior al 1.500 A.P.

4.2.3.-La Tradición Planáltica: Se diferencia en los complejos culturales (subtradiciones) Taquará e Itararé. Como su denominación lo indica su población se centra en el planalto, al sur del Paranapanema, pero también se dispersó al litoral atlántico adyacente. Los asentamientos se caracterizan por tener "casas pozo", básicamente los que están localizados en lugares altos entre $800-1.000 \mathrm{msnm}$; algunos además incluyen otras estructuras: túmulos y cordones generalmente circulares, montículos y también galerías o "nichos" excavados.

De su cultura material se han detectado cerámica y diversos artefactos: líticos tallados y pulidos, de hueso, concha y madera; restos faunísticos de la subsistencia y hasta textilería. También se han detectado restos esqueletarios humanos.

Si bien se mantuvieron la mayor parte del tiempo como cazadores - recolectores, finalmente incorporaron la horticultura, quizás cuando se contactaron con los Guaraníes.

Del complejo Taquará se han detectado unos 225 sitios. Su distribución geográfica se restringe básicamente al Planalto meridional, al sur del río Iguazú. En la Mesopotamia pobló solo algunas zonas de Misiones, a estas manifestaciones las he denominado como tipo Cultural Eldoradense. Los sitios se emplazan generalmente en lugares altos (más de $500 \mathrm{msnm}$ ) y en donde predominan las formaciones vegetales selva subtropical, selva araucaria, selva en galería, sabanas (campos). La cerámica no es muy abundante, su cocción es oxidante pero incompleta, el tratamiento de la superficie fue alisado o pulido y la mayoría tiene diversas decoraciones plásticas (Ej.: Punteado, Impreso, Inciso, Estampado). Las formas de las vasijas son distintivas y algunas de alto tamaño. Aparentemente esta entidad tuvo sus ancestros, vínculo con la tradición Humaita. Ya que los conjuntos líticos tienen notorias semejanzas con los de esta entidad. La cronología la sitúa entre 1.850 y 300 A.P.

4.2.4.-Tradición Ribereña Paranaense: Se le incluyen las siguientes manifestaciones: complejo Goya-Malabrigo, complejo Lechiguanas, tipo cultural Iberá, tipo cultural Paraná. Seguramente se le podrán definir diversos tipos culturales. Pobló la llanura aluvial y algunas de sus zonas adyacentes del bajo Paraná y su delta (desde la confluencia con el Paraguay hasta su desembocadura) y el bajo Uruguay. Su expansión se restringe a esa zona meridional, baja de la cuenca del Plata. Lo que la caracteriza básicamente es el tipo de ambiente ocupado, las características de su cultura material (Ej. la cerámica) y rasgos de su adaptación.

Del complejo Goya- Malabrigo se han detectado sitios en la llanura aluvial del Paraná, desde las localidades de Goya y Malabrigo hasta el Delta. Los sitios se emplazan en los lugares levemente elevados (albardones, médanos, lomas de arena, dunas y terrazas 
fluviales) de varios ámbitos de la llanura aluvial (márgenes elevados del curso central, de los riachos, lagunas, bañados, en islas y el margen final de la llanura).

La cerámica tiene bastante buena manufactura, cocción y decoración. Los colores que muestra son varios (naranja, rojo-ladrillo, sepia, gris oscuro o claro, crema, beige). Las superficies están bien alisadas o pulidas, muestran diversas decoraciones plásticas y muy llamativas (Ej: Surco rítmico, Punteado, Inciso, Impreso), también algunas están pintadas o engobadas (rojo o blanco). Lo mas típico de esta cerámica son los apéndices o aditamentos zoomorfos que tienen las vasijas, predominan los psitácidos (loros y cotorras). Las formas de vasijas más típicas son escudillas, platos, fuentes y ollas de contorno simple, ollas globulares restringidas y otras de contorno compuesto; presentan a veces asas, vertederos y los apéndices. Además de la cerámica se han detectado diversos artefactos de hueso o concha; los líticos tallados o pulidos son muy reducidos y rústicos. También restos faunísticos y en algunos sitios restos esqueletarios humanos.

Las dataciones, aunque no son numerosas, le otorgan una cronología entre 1.500 y 400 A.P.

El complejo Lechiguanas es una entidad que pobló el delta del Paraná, básicamente se detectaron sitios en la isla Lechiguanas I y Cañada Honda. Lo que la caracteriza es la cerámica, que tiene buena manufactura y buena decoración plástica o pintada. Las técnicas de decoración plástica son: Surco Rítmico, Inciso y Punteado; los motivos son sólo geométricos formando guardas complicadas. La pintura es sólo roja. Las formas de las vasijas son de contorno simple y relativamente pequeñas (ollas globulares o subglobulares, escudillas, platos hondos y playos). También la caracterizan artefactos de huesos de buena manufactura y diversidad. No se cuenta con dataciones para poder establecer su cronología.

El tipo cultural Iberá pobló el Estero Iberá y en riachos vinculados o próximos al mismo. En el estero se emplazan en isletas o márgenes de sus lagunas. En varios casos son pequeños montículos y conchales. En la capa arqueológica predominan valvas de moluscos, a la que se asocian tiestos cerámicos, algunos instrumentos líticos y de hueso, también hay abundantes restos faunísticos. Además en un sector del asentamiento suelen aparecer enterramientos humanos primarios. La cerámica muestra superficies alisadas y decoradas, los colores predominantes son sepia, gris oscuro y pardo oscuro. Las técnicas de decoración plástica aplicadas son: Surco Ritmico, Inciso, Punteado Ritmico en impresión. Los instrumentos óseos son arpones o puntas de proyectil, punzones y perforadores. Los artefactos líticos tallados son escasos y rústicos. No se cuenta todavía con dataciones para establecer su cronología.

\section{3.-Entidades Ceramolíticas Horticultoras}

4.3.1.-Tradición Tupiguaraní: Ya ha sobrepasado el millar de sitios descubiertos. Fue la entidad que pobló mayor cantidad de zonas de la cuenca del Plata y la que tuvo mayor demografía. Aunque no ocupó todas las zonas de esta cuenca se disperso por casi todo su territorio. Las más intensamente pobladas fueron: cuencas del Paraná alto y medio, alto Uruguay, Paraguay, Iguazú, Jacuí, Ijuí y el litoral atlántico adyacente a la cuenca. 
En la Mesopotamia el norte de Corrientes, Misiones y el delta del Paraná. Prevaleció la ocupación de las zonas con climas tropical y subtropical, con altas precipitaciones y ambientes selvaticos. Las aldeas estaban generalmente al margen de un humedal destacado. El tamaño de los asentamientos es variable, entre 1.000 y $25.000 \mathrm{~m} 2$, incluyen generalmente manchones de terra preta.

Cuando arribaron a esta cuenca ya disponían de cerámica y horticultura. La cerámica por su manufactura, decoración plástica (Ej.: Corrugado, Unguiculado, Brochado, Inciso, Punteado), pintada y las formas de las vasijas es muy característica y de buena calidad. Además de cerámica en los sitios se detectan escasos artefactos líticos tallados y pulidos y de hueso. Las vasijas muestran diversidad de tamaños, formas y decoraciones. Se detectan también diversos adornos e instrumentos de cerámica (Ej. pipas) y de hueso.

Las dataciones más antiguas son 2.200 A.P. y se extiende hasta 200 A.P

4.3.2.-Tradición Vieira: Esta entidad pobló el noreste de Uruguay y el extremo sureste de Brasil. Los sitios están localizados próximos a las laguna Merin y Dos Patos y a algunos riachos y bañados y la planicie costera atlántica. La mayoría se emplazan en montículos y cerritos construidos, se distinguen claramente del paisaje circundante por su elevación y/o por estar cubiertos por árboles. Los vestigios arqueológicos son cerámica, artefactos líticos y óseos, restos faunisticos y enterramientos humanos. La cerámica más temprana es de manufactura rústica, la decoración reducida y simple (Ej.: Punteado, Pseudo digitado, Inciso, Impreso), con el paso del tiempo se mejora y diversifica.

\section{5.-Proveniencia, migración y dispersión de las entidades culturales}

No se dispone todavía evidencias para poder confirmar plenamente cómo se gestaron, se iniciaron, desde dónde arribaron, si llegaron de otra área y cómo se dispersaron las entidades precerámicas, pero sí ya se cuenta con algunos datos que al menos sugieren una interpretación preliminar.

Por las dataciones y la localización de los sitios detectados surge la posibilidad que Paleoindígena arribó al río Uruguay desde el sudoeste o desde el norte y también de que haya emergido de previas entidades que poblaban esta región, que no tenían tecnología sofisticada bifacial y carentes de puntas de proyectil, que alrededor de 12.000 A.P. se contactaron con entidades de la Pampa que tenían una tecnología sofisticada y puntas de proyectil con específica morfología. La posibilidad de un arribo desde La Pampa lo sugiere además la similitud climática y ambiental que había en ese momento.

En el 10.000 A.P. Paleoindígena ya tenía una dispersión en el Uruguay medio, tuvo su climax y mayor dispersión al inicio del Holoceno. A partir del 9.200 A.P. fue decreciendo y finalmente en el 8.500 ya había desaparecido de esa región, aparentemente migró hacia el este, borde meridional del Planalto, motivada por un cambio climático bastante impactante muy árido y caluroso y la llegada de cenizas volcánicas que formó un manto que puede haber afectado también la vegetación y los animales. 
Como las dataciones más antiguas de la tradición Umbú están en sitios localizados en esa misma región del Planalto meridional donde se trasladó Paleoindígena, esto sugiere que se gestó de esta otra entidad. El haberse trasladado y ocupado una ambiente distinto, con distintas materias primas quizás le gestó a Paleoindígena diferenciar el conjunto lítico y las estrategias de subsistencia y asentamiento, lo que motivó que se gestara tradición Umbú.

Al inicio del Holoceno medio (8.000 A.P.) se aumentó la dispersión y arribaron a esta cuenca algunas nuevas entidades; quizás porque a partir de ese momento se intensificó y prevaleció el clima cálido y húmedo.

Umbú tuvo una dispersión a partir del 7.000 A.P. desde el sureste del planalto hacia el oeste y el sur y población más intensiva a partir del 6.000 A.P. que se intensificó en el 4.500 A.P.; esto pudo estar vinculado a cambios climáticos que les vino bien a su adaptación cultural. En comparación con las otras entidades preceramicas Umbú fue la que más se extendió, se dispersó en esta cuenca con el paso del tiempo y fue la que ocupó ambientes más diversos y la que tuvo una gran persistencia en su tecnología lítica. Umbú tuvo una alta dispersión en el río Uruguay y sus afluentes y en el Planalto meridional. En el alto Paraná y sus afluentes se han detectado pocos sitios, en el medio y bajo Paraná no se han detectado.

Humaitá arribó a esta cuenca desde el norte, puede tener sus ancestros en el noreste y/o centro de Brasil (Piauí, Minas Gerais, Matto Grosso, Goiania), ya que allí hay entidades con tecnología lítica y morfología con algunas semejanzas y con dataciones de más de 10.000 A.P. Las evidencias disponibles indican que Humaitá pobló inicialmente esta cuenca en tramos meridionales del alto Paraná y el alto Uruguay entre 9.000 y 8.000 A.P. Luego se expandieron hacia zonas del este y sur del Planalto de manera gradual, y también al río Uruguay medio y al Paraná medio.

Ivaí arribó también desde el norte y aparentemente de las mismas zonas que Humaitá, pobló inicialmente en los afluentes del Paraná (Paranapanema e Ivaí) alrededor del 7.000 A.P. se desarrolló por un tiempo allí y luego se dispersaron hacia el sur por el Paraná llegando hasta los Salto de Apipé y al Uruguay medio hasta el Salto Grande.

Las evidencias disponibles indican que Humaitá e Ivaí tuvieron una dispersión mas intensa en el Holoceno medio, básicamente durante el Optimun Climaticun. Umbú en cambio durante los eventos climáticos áridos. Se dispersaron hacia el sur probablemente por la tropicalización de las zonas meridionales de esta cuenca, que pasaron a tener cierta semejanza con las zonas del norte previamente pobladas. Ocuparon prioritariamente lugares donde existían afloramientos rocosos en el río y en los márgenes de los mismos. Las tradiciones Humaitá e Ivaí tuvieron alto poblamiento a partir del 6.000 A.P. .

Por varios miles de años las tradiciones Umbú, Humaitá e Ivaí fueron contemporáneos en la cuenca del Plata y poblaron algunas mismas zonas, pero no hubo una ocupación simultánea de los mismos espacios, se reemplazaron poblando esas mismas zonas en distintos momentos. Las dataciones sugieren que la población, la dispersión, la alternancia en los mismos lugares fue cuando hubo alteraciones en el clima y en los ambientes. Así es como se pudo gestar la alternancia en la ocupación de los mismos espacios por diferentes 
entidades. Los espacios que estas distintas entidades poblaron con mayor intensidad tienen diferencias ambientales.

La Tradición Tupiguaraní arribó a esta cuenca desde la zona centro - meridional de Amazonia entre el 3.000 y el 2.000 A.P.. Todavía no se puede confirmar plenamente la ruta o rutas de acceso y la zona de esta cuenca primeramente habitada, a la que llegó inicialmente, si fue el alto Paraná o el Paraguay y Paraná medio (Rodríguez 2005a). Es la entidad que tuvo la mayor dispersión y el poblamiento mas intensivo en la cuenca del Plata, y que llegó a tener la mayor relevancia, aunque fue una de las últimas en arribar.

En la tradición Planáltica, Taquará se gestó de Humaitá, e Itararé de Ivaí. En Sabanas Bajas el tipo cultural Salto Grande y el Yacyretá III también se gestaron de Ivaí.

Planáltica tuvo una dispersión bastante extensa en el planalto, se extendió en la zona central de esta cuenca y también al litoral adyacente. Ribereña Paranaense tuvo extensa dispersión en casi todo el bajo Paraná, el Delta, el bajo Uruguay y el estero del Iberá. Sabanas Bajas y Platense no tuvieron tanta dispersión.

La tradición Ribereña Paranaense probablemente se gestó de pueblos que arribaron (migrando o dispersándose) desde el Pantanal o el alto Paraguay. Ya he detectado que algunos sitios en la zona norte del bajo Paraná, el Chaco adyacente y en el estero del Iberá, tienen semejanzas en la decoración cerámica, los asentamientos, los enterratorios humanos, con algunas fases de la tradición cerámica Pantanal; lo que sugiere que pueden ser sus antecedentes genealógicos. En la llanura del bajo Paraná se llegó a partir del 1.200 A.P. a una alta demografía, expansión y dispersión de la tradición Ribereña Paranaense. Pero la evidencia que se dispone sugiere que ese crecimiento demográfico y su dispersión fueron lentos y graduales, llevó varias centurias. Aunque esto produjo alguna diversificación cultural, lo que generó diversos Tipos Culturales, fue dentro de la misma Tradición Cultural, por eso en los rasgos básicos prevaleció la semejanza y homogeneidad cultural.

La dispersión de Sabanas Bajas, Platense y Vieira fue más reducida que las antes mencionadas. Platense se redujo al bajo Uruguay y algunos de sus afluentes y sectores del Delta y margen río de La Plata. Sabanas Bajas al Uruguay medio y zonas adyacentes del interior y un sector del Paraná medio.

\section{6.-El proceso de desarrollo Cultural en la Cuenca del Plata (Características)}

Por los sitios que se han detectado hasta ahora al final del Pleistoceno e inicio del Holoceno esta cuenca tenía un muy escaso poblamiento y restringido a muy pocas zonas. Además aparentemente no existía diversidad cultural, se han detectado solamente dos entidades. Desde la década del 1980 por las evidencias detectadas, sobre todo las dataciones, se ha interpretado como la que pobló inicialmente esta área fue la tradición Paleoindígena con una antigüedad de 12.000 A.P. En las ultimas décadas fueron surgiendo algunas evidencias en regiones vecinas (noreste y centro de Brasil) y recientemente también en esta cuenca que plantean al menos el interrogante si esta área no fue inicialmente poblada por otras entidades con industrias líticas toscas (rústicas) y sin puntas de proyectil. Recientemente se ha detectado la existencia de otra entidad en el río Uruguay medio, a la que he denominado 
CauceUrú (Rodríguez 2005b) y que podría haber precedido a Paleoindígena por su localización geológica y estratigráfica y porque tiene una industria lítica muy tosca y que tiene semejanzas con las de sitios hallados en el norte de la Cuenca del plata y regiones vecinas (adyacentes), con dataciones muy antiguas que se están extendiendo hasta 29.000 A.P. (Vilhena 2005).

La diversificación cultural y la ocupación de otras zonas se inicia a partir del Holoceno (entre 10.000 y 8.000 A.P.), esto se intensifica en el Holoceno medio. Las alternancias climáticas del Holoceno fue uno de los motivos que generó o promovió la migración, el arribo y la dispersión de varias entidades en esta cuenca. Al inicio del Holoceno medio (8.000 A.P.) con la intensificación del cambio climático, mas cálido y mas húmedo, es cuando arriban nuevas entidades a la cuenca del Plata y los que previamente la poblaban se trasladaron o dispersaron a otras zonas. Por esto aumentó el poblamiento, la dispersión y la diversidad cultural a partir del Holoceno medio. Esto se intensificó un poco más a partir del 6.000 A.P. cuando prevalecía el evento Optimun Climaticum, aunque la mayor demografía, la alta diversidad cultural y la ocupación de casi todas las zonas de la cuenca y la gran dispersión regional de algunas entidades ocurrió recién a partir de 3.000 A.P..

Las tradiciones Humaitá e Ivaí se dispersaron y se destacaron como entidades en esta cuenca a partir del 7.000 A.P. Ivaí recién llegó en el 6.000 A.P. a la Mesopotamia.

En las tradiciones Paleoindígena y Umbú persistió la misma tecnología lítica, con pocas modificaciones, los cambios entre estas dos entidades y en la extensa existencia y dispersión de Umbú se verifica solamente en aspectos estilísticos y morfológicos de las puntas de proyectil y en los componentes (tipos) de los conjuntos líticos. Estas dos entidades tienen algunas semejanzas con Ivaí con relación al tallado unifacial y algunos tipos de artefactos así manufacturados. Esto sugiere que pudieron haber tenido un ancestro genealógico común. El tallado unifacial restringido y tosco ya estaba incluido en las entidades más tempranas, se difundió en diversas entidades y persistió hasta épocas tardías. Humaitá se diferencia más notoriamente de esas tres entidades mencionadas.

En las diferentes tradiciones preceramicas que poblaron esta cuenca se ha podido verificar que por varios milenios no produjeron cambios significativos ni sustanciales en sus tecnologías líticas, si tuvieron algunos cambios graduales con el paso del tiempo y la dispersión espacial en sus conjuntos de artefactos (Ej. morfología, tipología, funcionalidad y/o porcentajes en sus componentes). En cada tipo cultural predominó la continuidad y la persistencia de la estabilidad tecnológica. También hubo una persistencia milenaria de algunos instrumentos específicos, en una misma entidad y en algunos casos en varias entidades. La ocupación de ambientes diferentes por la misma entidad cultural es lo que promovió algunos cambios y diversificación de los distintos componentes (rasgos) de la cultura (Ej. estrategias de subsistencia, tecnología, asentamientos).

Se ha podido verificar algunas evidencias que las características ambientales impactaron las estrategias de subsistencia, de residencia y la tecnología. Estas estrategias son respuestas a las características del ambiente natural y también al contexto social. 


\section{Introducción de la cerámica}

Todavía no se dispone de evidencias para poder confirmar plenamente si la técnica para manufacturar cerámica se gestó en algún lugar del área o llegó desarrollada por difusión desde otra área. Pero aparentemente esta tecnología no fue inventada en esta cuenca sino fue un préstamo de entidades de regiones vecinas o de algunas entidades que ya la disponían y que arribaron a esta cuenca en esos momentos. Podría haber sido la llegada de la tradición Tupiguaraní a esta cuenca lo que les aportó el conocer esta tecnología y/o también alguna otra del Pantanal y/u otra proveniente desde el sur (zona pampeana). Las evidencias y los datos disponibles sugieren que la cerámica fue introducida en el área entre el 3.000 y el 2.500 A.P. Es coincidente con un evento climático de aridez lo que puede haber promovido migraciones o dispersiones de entidades de otras áreas que ya disponían de la cerámica y que las entidades que ya poblaban esta cuenca pudieran haberse contactado con ellas o otras de áreas vecinas.

En la mayoría de los casos la cerámica se incorporó como innovación en las entidades precerámicas que ya poblaban esta región. Las entidades que poblaron la llanura aluvial del bajo Paraná y los esteros del Iberá justamente a partir del 2.000 A.P., si es muy probable que ya llegaron como ceramolíticas y que sus ancestros poblaron el Pantanal, ya que se detectan semejanzas en la cerámica de estas tres regiones.

La incorporación de la cerámica provocó un gradual empobrecimiento de los conjuntos líticos, tanto en la tecnología, como en la morfología de los artefactos. Varias de las entidades ceramolíticas mantuvieron algunos rasgos similares y bastante rusticidad en la manufactura, decoración, cocción de la cerámica. Sabanas Bajas se inició como la más tosca y simple y se mantuvo así en su desarrollo y dispersión. Planaltica muestra al menos una decoración, formas y tamaños de las vasijas mas complejas. Platense mejora sobre todo en los motivos de la decoración. Ribereña Paranaense exhibe mejores características con relación a las mencionadas, alcanzó la mayor sofisticación en la decoración y en el modelado de los apéndices zoomorfos. La tradición Tupiguaraní es la que tuvo desde su arribo un buen dominio de la tecnología de manufactura y diversidad en la decoración, las formas y el tamaño de las vasijas, además fue muy típica, muy distintiva.

Por las evidencias disponibles casi todas las entidades ceramoliticas se iniciaron y se mantuvieron como cazadores-recolectores. Planáltica se inició como cultura cazadoresrecolectores, pero posteriormente, quizás cuando tuvo contacto con la Tupiguaraní incorporó la horticultura. También algunos tipos culturales de Ribereña Paranaense incorporaron esa innovación, pero por lo detectado muy poco antes de la Conquista y escasas entidades.

En base a lo mencionado y otras evidencias detectadas a continuación se exponen algunas propiedades (características) del proceso de desarrollo en esta cuenca:

-Cada región ecológica presenta un desarrollo cultural con modalidad propia que exhibió cierta continuidad al menos por una etapa. No se detectan interrupciones o reemplazos abruptos sino más bien cambios graduales.

-Largo tiempo de persistencia de las mismas entidades culturales en cada región. Y por lo general sin introducir cambios significativos por mucho tiempo. 
-Escasas rupturas, cambios y reemplazos en los desarrollos de entidades de algunas regiones, observándose una llamativa continuidad y persistencia en algunas culturas.

-Las rupturas en las secuencias y los cambios en los procesos aparentemente se gestaron más por las causas (agentes) naturales (cambios climáticos y ambientales) que culturales.

-Si bien las innovaciones relevantes, como la cerámica y la horticultura, no se inventaron en esta cuenca, se tomaron prestadas, fueron episodios esporádicos, puntuales. A pesar de que estuvieron comunicados, interrelacionados con zonas vecinas no hubo una ingerencia externa habitual ni de otras innovaciones relevantes.

-La regionalización se va haciendo más caracterizada y mejor definida con el paso del tiempo. Hay una mayor fragmentación de las tradiciones, diversificación de tipos culturales. También mayor especificidad de la mayoría de las entidades con ambientes específicos.

-Se comienza a percibir un aumento demográfico y probablemente menos movilidad recién a partir del 2.000 A.P. con el advenimiento de las entidades ceramolíticas.

-Aparentemente esta cuenca tuvo mayor diversidad cultural que áreas vecinas (El Chaco, La Pampa, El Centro)esto puede estar relacionado a la diversidad ambiental y climática que tiene.

-Por lo general la mayor estabilidad en los desarrollos regionales fue en lo tecnológico. Probablemente las alternancias climáticas y ambientales deben haber fomentado algunos cambios en sus estrategias adaptativas (Ej. sistemas de subsistencia y asentamientos).

-La tecnología lítica generalmente tuvo su mejor calidad cuando se gestó, no se detecta un perfeccionamiento con el paso del tiempo, sino se mantiene igual o decae. También es sugestiva la amplísima distribución espacial y temporal de algunos artefactos tallados y pulidos, repitiéndose en diversas entidades (Ej. raspadores, hachas, bolas, molinos, piedras con hoyuelos, choppers).

-Hubo al menos durante algunos periodos bastante estabilidad en varias entidades. Lo cual no conduce a una complejización adaptativa.

\section{7.-Adaptación Cultural}

Las sociedades prehistóricas manifiestan un uso diferencial del espacio en relación con las características del ambiente ocupado (Wandsnider 1992). Para las que tuvieron una modalidad de subsistencia cazadora-recolectora uno de los tópicos relevantes son las propiedades que tienen los recursos naturales que pueden explotarse: su distribución, abundancia, diversidad, persistencia y predicción de los mismos, (Winterhalder 2001). A esto se deben afinar las estrategias adaptativas de las culturas, aunque la respuesta que da cada cultura al mismo ambiente puede no ser igual sino diferente. Para algunas culturas ciertas propiedades del medio ambiente pueden ser apropiadas y para otras negativas (Ej. la diversidad microambiental).

Aunque el medio ambiente puede tener un rol relevante en esos aspectos de la Cultura, esto no significa que predomine como única causa, siempre hay un mutuo efecto entre lo natural, lo social y lo cultural. Estoy de acuerdo con la postura teórica que sostiene 
que una interpretación de la Cultura o alguno de sus componentes no puede realizarse en forma reduccionista o determinista, que hay que abordar varias dimensiones, multitemática, interdisciplinaria, holística.

La mayoría de las entidades que poblaron esta cuenca fueron cazadores-recolectores y se mantuvieron así por largo tiempo. Ocuparon los márgenes de relevantes humedales (ámbitos ribereños), quizás unos de los motivos que los incentivó a esto fue que allí disponían buena cantidad y diversidad de recursos naturales (faunísticos y vegetales) y los podían explotar sin mayores dificultades. Hasta los horticultores se mantuvieron ocupando estos lugares.

La dispersión y ocupación de distintos ambientes por la misma entidad cultural motivó que se produjeran algunos cambios adaptativos en la tecnología, subsistencia, estrategias de explotación de recursos y patrones de asentamiento, lo que promovió la generación de distintos tipos culturales.

La Tradición Paleoindígena ocupó la cuenca del río Uruguay medio durante la transición climática Pleistoceno-Holoceno, cuando se desvanecían las condiciones frías y áridas de la era glacial y se afianzaban gradualmente las templadas y húmedas, con alternancias climáticas. Por las evidencias detectadas tuvieron una estrategia adaptativa generalizada no especializada.

La Tradición Umbú ocupó ambientes diversos, adecuando su adaptación a esos distintos biomas. Se tiende a considerar que ocupó preeminentemente espacios abiertos (praderas, sabanas) y también en los ecotonos (transición de una a otra) de esas formaciones vegetales o en lugares donde podía tener fácil acceso a dos o tres ámbitos ecológicos. En el planalto estuvieron generalmente alejados de los cursos principales, a diferencia de lo que sucedió en la zona más llana y meridional.

La tradición Humaitá tiene localizados sus asentamientos en zonas elevadas y cubiertas por selva subtropical, en muchos casos en ecotonos de esa formación con la selva araucaria o en zonas próximas a esta, su adaptación dependería de esos dos ámbitos ecológicos.

Ribereña Paranaense muestra una dependencia bastante estricta de un ambiente específico, humedales muy típicos (la llanura extendida del bajo Paraná y esteros o bañados), esos humedales les aportaron alta diversidad y cantidad de recursos (fauna y vegetales) que basó su subsistencia en la explotación de diversos recursos acuáticos y terrestres (diversos peces, carpincho, nutria, cérvidos, armadillo, aves, cuis). Por las evidencias detectadas incorporaron la horticultura sólo algunas comunidades y tardíamente (poco antes que llegara la Conquista). Como se puede verificar la gran variabilidad ecológica existente en la llanura aluvial del bajo Paraná ha sido aprovechada por los grupos prehistóricos para el emplazamiento de sus asentamientos. Los sitios se localizan en distintos terrenos de dicha 1lanura aluvial. Esta no muestra cotas superiores a los $30 \mathrm{~m}$ y más bien la mayor parte está por debajo de los $10 \mathrm{~m}$. Los sitios localizados en los bordes de las terrazas y en las dunas eólicas son los que se emplazan en cotas más elevadas (entre 15 - $30 \mathrm{~m}$ ), 
Planáltica en su sistema adaptativo tuvo relevancia la explotación de recursos en la selva de araucaria, allí no solo explotaban relevantes recursos vegetales sino también faunísticos que también en algunos momentos llegaban a consumir los frutos de esos vegetales. Como para esto se mantendrían en esos lugares hasta el invierno fue los que les gestó las casas pozo, para poder superar el frío intensivo que tenían esos lugares selváticos elevados del Planalto. Como procesaban y almacenaban los recursos obtenidos esto les condicionaba la permanencia en el mismo lugar. Al menos algunos tipos culturales y en un momento ya quizás tardío incorporaron la horticultura.

Sabanas Bajas tuvo una estrategia adaptativa muy generalizada. Con la práctica de la recolección, la caza y la pesca, aunque se restringieron a lo ribereño (los cursos y sus márgenes) pudieron explotar alta diversidad de recursos. Por eso los campamentos se localizaban al margen del río y la movilidad residencial se restringió adyacente a los cursos y pasaban de un humedal a otro incluso cuando se trasladaron al interior.

La tradición Tupiguaraní (cultura Guaraní), fue la entidad que tuvo en esta cuenca un modo de vida, una estrategia adaptativa más compleja y significativa que las antes mencionadas. No solo por tener la horticultura además de la caza, pesca y recolección, sino también destacados procesamiento de los recursos alimentarios, asentamientos (aldeas) mas complejas y mayor sedentarización y organización social. Como su hábitat original había sido la Amazonia, se mantuvieron con una estrategia adaptativa semejante a los que poblaron ese ambiente, aunque en la cuenca del Plata ocuparon otros tipos de ambientes.

Como se puede verificar por lo mencionado hubo tendencia a permanecer como cazadores/recolectores y a mantener una estrategia adaptativa generalizada no especializada y bastante estabilidad. Esto puede estar relacionado a que se tuvo buena potencialidad y abundancia de recursos, a las alternancias climáticas y ambientales que hubo en el Holoceno y a que no llegaron a un desarrollo cultural complejo, porque esas propiedades no les exigen explorar nuevas estrategias adaptativas más complejas, lo cual conduce a cierta estabilidad. Los horticultores si tuvieron algún nivel de especialización y complejizaron las estrategias.

Los cambios climáticos y alteraciones ambientales reiterados del Holoceno parecen haber motivado algunas modificaciones adaptativas en algunas entidades. 
Folia Histórica del Nordeste, Nº 16 (Resistencia, 2006) IIGHI, CONICET - IH, UNNE)

Cuadro 1

Secuencia Cultural (esquema cronológico) de las Entidades Culturales que poblaron diversas regiones de la Cuenca del Plata.

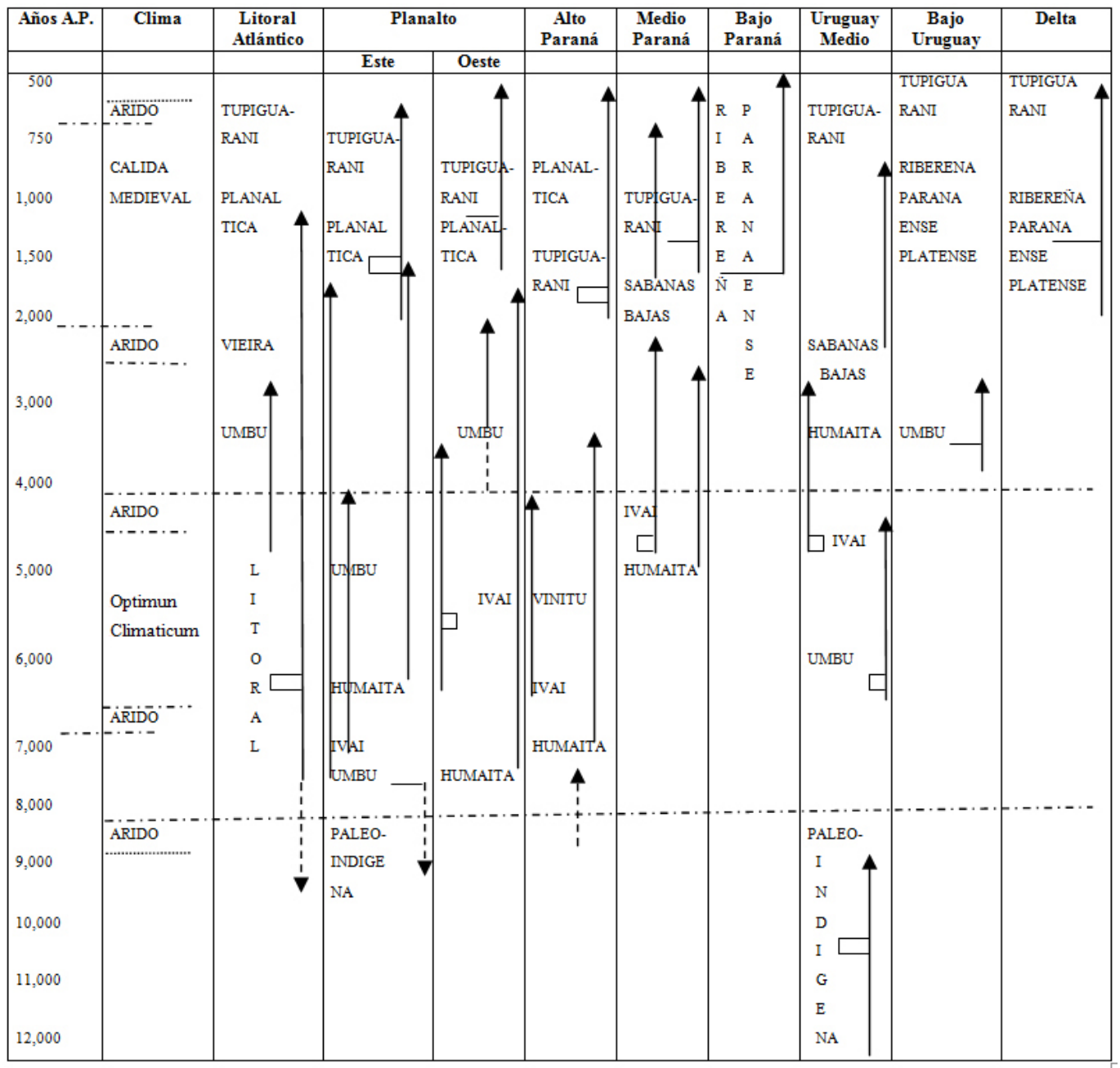




\section{Bibliografía}

Behling, H. 1998. Late Quaternary vegetational and climatic changes in Brazil. Review of Palaeobotany and Palynology 99. Elsevier, pag: $143-156$.

Behling, H. y R. Negrelle. 2001. Tropical rain forest and climate dynamics of the Atlantic lowland, Southern Brazil, during the late Quaternary. Quaternary Research 56: 383 - 389.

Clapperton, C. 1993. Quaternary Geology and Geomorphology of South America. Elsevier. London.

Bracco Bocsar, R.; L. Cabrera y J. Lopez Mass. 2000. La Prehistoria de las Tierras Bajas de la Cuenca de la Laguna Merín. Arqueología de las Tierras Bajas. Coirolo y Bracco Editores. Montevideo.

Ceruti, Carlos. 1992. Cambios climáticos y poblaciones preshistóricas en el Litoral Argentino. M. Iriondo (Editor) El Holoceno en la Argentina 1: 39-49. CADINQUA. Paraná

Chmyz, I. 1983. Sétimo Relatorio do Projecto Arqueológico Itaipú. Itaipú/Iphan, Curitiba.

Iriondo, M. 1991. El Holoceno en el Litoral. Comunicaciones del Museo Florentino Ameghino.Vol. 3 (1). Santa Fe.

Iriondo, M y N. García. 1993. Climatic variations in the Argentine plains during the last 18,000 years. En: Paleogeography, Paleoclimatology, Paleoecology, 101. Pp:209-220. Elsevier, Amsterdan.

Iriondo, M. 1999. Climatic changes in the South American plains: Records of a continent-scale oscillation. Quaternary International 57 - 58, pp: 93 - 112. Pergamon Press.

Kashimoto, E. y G. Martins. 2000. Panorama Arqueológico da Margen Direita Do Río Paraná, Ms: Do Povoamento por Caçadores-Coletores a Indios Guaranís Coloniais. CLIO 14. Anais da X Reuniâo Cientifica da SAB. UFPE. Pp. 299 -352.

Ledru, M.; M. Salgado-Labouriau y M. Lorscheitter. 1998. Vegetation dynamics in southem and central Brazil during the last 10.000 yr B.P. Review of Paleobotany and Palynology 99. Elsevier.

Mentz Ribeiro, P. A. 1991. Arqueología do vale do río Pardo, Río Grande do Sul, Brasil. Tese (Doutorado em Historia). Pontificia Universidade Católica do Rio Grande do Sul. 654 pp.

Miller, E. Th., 1987. Pesquisas arqueológicas paleoindígenas no Brasil ocidental. Estudios Atacameños 8, $37-61$.

Morais De, J. L. 2000. Arqueología da regiâo Sudeste. Universidade de Sao Paulo, Revista USP 44, $194-217$.

Morrone, Juan 2001. Biogeografía de América Latina y el Caribe. M \& T SEA. Zaragoza

Oliveira, J. Eremites. 2002. Da Pré- História a História Indígena: (Re) Pensando a Arqueología e os Povos Canoeiros do Pantanal. Tese de Doutorado. Porto Alegre. PUCRS.

Rodríguez, J. y A. Rodríguez. 1985. Proyecto antropológico-ecológico Salto Grande. Concordia. Editorial de la Universidad Nacional de Entre Ríos.

Rodríguez, J. A. 1986. Planteamientos Teóricos y Metodológicos referidos al Diseño de Investigación. Cuadernos Instituto Nacional de Antropología, No: 11. Buenos Aires.

Rodriguez, J. A. 1999. Evolución de la tecnología prehistórica en el Sudeste de América del Sur. Formativo Sudamericano, Una Revaluación. P. Ledergerber (editor). Ediciones Abyayala. Ecuador. pp. $314-327$.

Rodríguez, J. A. 2004. Poblamiento Prehistórico de la Mesopotamia Argentina. Folia Historica del Nordeste 15: 129-146. Instituto de Investigaciones Geohistóricas. Resistencia

Rodriguez, J.A. 2005a . El Proceso de Migración y Dispersión de la Tradición Tupiguaraní en la Cuenca del Plata. En Actas del XV Congreso Nacional Arqueología Argentina. Rio Cuarto.

Rodríguez, J. A. 2005b. El Poblamiento Inicial de la cuenca del río Uruguay medio. En Actas del XV Congreso Nacional Arqueología Argentina. Rio Cuarto.

Roth, L y M. Lorscheitter. 1989. Palynology of a peat in Parque Nacional de Aparados da Serra, Río Grande do Sul, Brazil. International Symposium on Global Changes in South América During 
the Quaternary. Special Publication 1: 56-59. Sao Paulo.

Salgado-Labouriau M.; M.Barberi; K.Ferraz-Vicentini; M.Parizzi. 1998. A dry climatic event during the late Quaternary of tropical Brazi. Review of Palaeobotany and Palynoloy 99. Elsevier, pp. $115-129$.

Schmitz, P. I. 1987. Prehistoric Hunters and Gatherers of Brasil. Journal of World Prehistory 1 (1), Plenum Press. Pp. 53-126.

Servant, M ; F. Soubiés; K. Suguio; B. Turcq, M. Fournier. 1989. Alluvial fans in southeastern Brazil as an evidence for early Holocene dry climate period. International Symposium on Global Changes in South América During the Quaternary. Special Publication 1: 75 - 77. Sao Paulo.

Silva Noelli, F. 2000. A Ocupaçâo humana na regiâo sul do brasil: Arqueología debates e perspectivas 1872 - 2000. Universidade de Sâo Paulo, Revista USP 44, 218 - 269.

Stevaux, J. C. 2000. Climatic events during the Late Pleistocene and Holocene in the upper Paraná river: correlation with NE Argentina and South-Central Brazil. Quaternary International 72. Pergamon Press, pp. $73-85$.

Turcq, B.; M. Pressinotti y L. Martin. 1997. Paleohydrology and Paleoclimate of the past 33.000 years at the Tamanduá river, central Brazil. Quaternary Research 47: $284-294$.

Vilhena Vialou, A. 2005. Presença Humana Durante o Pleistoceno No Centro Da Amérique Do Sul. Actas Resumenes XI Congreso Nacional de Arqueología Uruguay. Salto.

Wandsnider, L. 1992. Archaeological Landscape Studies. En Space, Time and Archaeological Landscapes. Editado por Rossignol, J. y L. Wandsnider. Plenum Press, New York.

Winterhalder, B. 2001. The behavioural ecology of hunter-gatherers. En: Hunter - Gatherers: an interdisciplinary perspective. Editado por Panter-Brick, C. R. Layton, P. Rowley, Cambridge University Press. United Kingdon.

\section{Resumen}

Este trabajo presenta una descripción e interpretación del poblamiento, el proceso de desarrollo y la secuencia cultural en la cuenca del Plata oriental, desde el inicio de su ocupación hasta el inicio de la Conquista. Para el análisis de estas temáticas es fundamental disponer de información sobre cómo es el territorio y el paisaje (ambientes) de esta área, por eso se exponen detalles del medio ambiente y el clima actual y cómo fueron desde el Pleistoceno final hasta el Holoceno reciente. También se expone una breve síntesis de las diversas entidades culturales que poblaron esta cuenca, cómo arribaron, se dispersaron y qué espacios ocuparon. Además de la difusión de estos temas, se los expone para que sirvan para verificar si hubo vínculos y algunas semejanzas o predominó la desconexión y las diferencias culturales entre esta cuenca y el Chaco meridional.

$<$ Cuenca del Plata $><$ Prehistoria $><$ Poblamiento $><$ Desarrollo $><$ Secuencia $><$ Cultural $>$ 


\begin{abstract}
This essay presents a description and interpretation of the human population, the development process and the cultural sequence in the oriental cuenca del Plata, since the first occupation until the start of the colonization. To analize these topics it is necessary to handle information about the territory and environments of this area; that is why I expose some details of the environment and actual climate and how they were since the final Pleistocene until the recent Holocene. It also expose a short syntesis (abstract) of the diverse cultural "entities" that inhabitated this cuenca, how they arrived and dispersed and which specific spaces of this cuenca they occupied. These subjects are not only presented for their diffusion, but also for it's contribution to the verification of the fact if there were links and similarities, or if what predominated was the disconection and cultural differences between this cuenca and the meridional Chaco.
\end{abstract}

$<$ Cuenca del Plata $><$ Prehistoric $><$ Population $><$ Development $><$ Sequence $><$ Cultural $>$ 